\title{
A pilot study of complementary and alternative medicine use in patients with fibromyalgia syndrome
}

\author{
Geoffrey C. WALL, Linda L. KRYPEL, Michael J. MILLER, Derek M. REES.
}

\begin{abstract}
${ }^{*}$
Fibromyalgia syndrome (FMS) is a complex disorder, with primary symptoms of sleep disturbances, pain, and fatigue. FMS is one of the most common reasons for patient visits to a rheumatologist. Previous studies have suggested that complementary and alternative medicine (CAM) use in patients with rheumatic diseases is common, but such data specific to FMS patients is limited. Objective: The following study sought to describe the prevalence of CAM use in a primary care practice of patients with FMS and assess whether these patients discuss CAM use with their physician, physician-extender, and/or pharmacist. Methods: A one-group cross-sectional survey design was implemented in a large, communitybased, private physician practice of patients diagnosed with FMS. A self-administered questionnaire was distributed during clinic visits. It solicited information related to demographic characteristics; FMS-specific health background; whether CAM use had been discussed with a health care provider; and the "ever-use" of common types of CAM. Respondents returned the questionnaire via US mail in a postage-paid, self-addressed envelope.

Results: A total of 115 surveys were distributed with 54 returned for analysis ( $47 \%$ completion rate). The sample was predominantly female, well educated and had a mean age of 55.6 years. All respondents were White. Most respondents (92.6\%) reported using some type of CAM. Exercise $(92.2 \%)$, chiropractic treatment $(48.1 \%)$, lifestyle and diet $(45.8 \%)$, relaxation therapy $(44.9 \%)$, and dietary and herbal supplements $(36.5 \%)$ were most commonly reported CAM therapies "ever-used" by respondents. Dietary and herbal supplements with the highest prevalence of "ever-use" were magnesium (19.2\%), guaifenesin (11.5\%), and methylsulfonylmethane (MSM) (9.6\%).

Respondents most commonly discussed CAM with the clinic rheumatologist and the primary care
\end{abstract}

*Geoffrey C. WALL. Pharm.D., BCPS, CGP. Associate Professor of Pharmacy Practice. lowa Methodist Medical Center, Drake University. Des Moines, IA (USA). Linda L. KRYPEL, Pharm.D. Associate Professor of Pharmacy Practice. Drake University, College of Pharmacy. Des Moines, IA (USA).

Michael J. MILLER, RPh, DrPH. Assistant Professor of Social and Administrative Sciences. College of Pharmac, Drake University. Des Moines, IA (USA).

Derek M. REES. Doctor of Pharmacy Candidate. College of Pharmacy. Drake University. Des Moines, IA (USA). physician ( $53.7 \%$ and $38.9 \%$, respectively). Only $14.8 \%$ of respondents discussed CAM with a pharmacist. However, a significantly higher proportion of respondents who "ever-used" dietary and herbal supplements discussed CAM with a pharmacist compared to those who never used dietary and herbal supplements [chi square $=6.03$, $p=0.014]$.

Conclusion: This pilot study suggests that CAM use is common in patients diagnosed with FMS. Compared to other healthcare providers, respondents were least likely to discuss CAM with a pharmacist. However, respondents who used dietary and herbal supplements were more likely to discuss CAM with a pharmacist compared to those who did not, suggesting the potential influence of pharmacist intervention.

Keywords: Fibromyalgia. Complementary Therapies. United Stated.

\section{RESUMEN}

El síndrome de fibromialgia (SFM) es un desorden complejo, con síntomas primarios de alteraciones del sueño, dolor y fatiga. SFM es una de las razones más frecuentes por las que los pacientes visitan al reumatólogo. Estudios previos han sugerido que es frecuente el uso de la medicina complementaria y alternativa (MCA) en pacientes con enfermedades reumáticas, pero tales datos relativos a SFM son escasos.

Objetivo: El siguiente estudio trató de describir la prevalencia de uso de MCA en atención primaria en pacientes con SFM y evaluar si estos pacientes comentan la MCA con sus médicos, o con sus auxiliares médicos y/o con el farmacéutico. Métodos: Se empleó un diseño de investigación transversal de un grupo de pacientes diagnosticados de SFM de un gran consultorio privado de un médico. Durante las horas de visita, se distribuyó un cuestionario auto-administrado. Solicitaba información relacionada con las características demográficas; antecedentes sanitarios específicos del SFM; si se había discutido la posibilidad de usar MCA con el profesional de la salud; y el uso "alguna vez" de los tipos frecuentes de MCA. Los respondentes retornaban el cuestionario por correo en un sobre pre-pagado.

Resultados: Se distribuyeron un total de 115 encuestas con 54 devueltas para análisis (47\% cumplimentación). La muestra era predominantemente mujeres, bien educadas y con 
una media de edad de 55,6 años. Todos los respondentes eran blancos. La mayoría $(92,6 \%)$ comunicaban usar algunos tipos de MCA. Los más frecuentemente comunicados como los que habían usado "alguna vez" eran ejercicio $(92,2 \%)$, tratamiento quiropráctico $(48,1 \%)$, estilos de vida y dieta $(45,8 \%)$, terapia de relajación $(44,9 \%)$, suplementos dietéticos y herbales $(36,5 \%)$. Los suplementos dietéticos y plantas medicinales con una prevalencia más alta fueron magnesio $(19,2 \%)$, guaifenesina $(11,5 \%)$ y metilsulfonilmetano $(9,6 \%)$. Los respondentes discutieron normalmente el uso de MCA con el reumatólogo y el médico de atención primaria $(53,7 \%$ y $38,9 \%$, respectivamente). Sólo el $14,8 \%$ de los respondentes lo había discutido con un farmacéutico. Sin embargo, una proporción mayor de respondentes que habían usado "alguna vez" suplementos dietéticos y plantas medicinales discutieron el uso de MCA con el farmacéutico que aquellos que nunca los habían usado [chi cuadrado $=6.03, \mathrm{p}=0.014]$.

Conclusión: Este estudio piloto sugiere que la medicina complementaria y alternativa se usa frecuentemente en pacientes diagnosticados de SFM. Comparados con otros profesionales de la salud, los respondentes discutían menos su MCA con el farmacéutico. Sin embargo, los que habían usado suplementos dietéticos y plantas medicinales discutían más fácilmente sobre su MCA con el farmacéutico que los que no los habían usado nunca, lo que apunta al posible papel del farmacéutico en este campo.

Palabras clave: Fibromialgia. Terapias complementarias. Estados Unidos.

\section{INTRODUCTION}

Fibromyalgia syndrome (FMS) is a complex disorder, with primarily musculoskeletal pain symptoms and fatigue, and is one of the most common reasons for patient visits to a rheumatologist. ${ }^{1}$ The clinical and economic burden of the disease in the U.S. is staggering, with an estimated $\$ 6000 / p t / y r$ spent on this disorder and with high levels of total disability leading to increased indirect costs. ${ }^{2}$ Unfortunately, the etiology of this widespread pain syndrome is uncertain, leading to a level of frustration on the part of patients, physicians, and other providers. ${ }^{3}$ No cure for the disorder yet exists and treatments (both pharmacotherapy and others) have been largely disappointing. ${ }^{4}$ In other examples of chronic diseases with less than optimal treatments (especially in rheumatic diseases) patients will often turn to complementary and alternative medicine (CAM). In most cases CAM is used adjunctively to allopathic medicine, but patients may completely stop allopathic treatment in favor of CAM as well. A study in patients with rheumatoid and osteoarthritis showed about $63 \%$ of patients in a group of rheumatologists' practices used CAM. ${ }^{5}$ The different types of CAM patients reported using included

chiropractic treatment, copper bracelets or magnets, herbal therapies, electrical stimulators, vinegar preparations, diet supplements, special diets, minerals or megavitamins, acupuncture, or spiritual healing. Interestingly, only about half of the respondents had told their physicians that they were using CAM in this study. As CAM can benefit as well as harm patients, it is vital that clinicians are aware of all treatments their patients are receiving. This is especially true with herbal medications, which may interact with other pharmacotherapy or cause adverse reactions. ${ }^{6}$ Until recently little data had been published on the use of CAM in a population of patients with FMS. One small webbased questionnaire study found that CAM use was relatively common in FMS patients and included herbal and vitamin use and massage therapy. ${ }^{7}$ Unfortunately this study did not confirm the diagnosis of FMS. Thus, the sample was too heterogeneous to generalize to FMS patients. Therefore, we conducted a pilot study in a primary care practice of patients with FMS to determine the type and prevalence of CAM use in their patients.

\section{METHODS}

A one-group, cross-sectional survey of patients diagnosed with FMS was conducted to profile prevalence of CAM use in a large, communitybased rheumatology practice in Des Moines, IA. Data were collected using an anonymous, selfadministered, questionnaire. A cover letter accompanied the questionnaire to describe the study and invite participation. Consent to participate was implied by voluntary completion and return of the questionnaire. The appropriate institutional review boards approved this study.

At the time of a clinic visit between February and November 2005, questionnaires were distributed to each of 115 patients diagnosed with FMS. One questionnaire was distributed per patient visit. A disclaimer was placed at the beginning of the questionnaire requesting not to complete it more than once in case a potential respondent received a second copy of the questionnaire at a subsequent visit.

The investigators based their survey content on a large study of CAM in general Rheumatology patients published in $1999 .^{5}$ The first section of the questionnaire solicited information related to each respondent's FMS-specific health background including time since FMS diagnosis, frequency of provider visits for FMS, and whether they had discussed the use of CAM with a physician, physician-extender, and/or pharmacist. The second section of the questionnaire documented "ever-use" of CAM ranging from physical treatments such as acupuncture and chiropractic treatment to pharmacologic interventions such as dietary and herbal supplements. A third section of the questionnaire included two open-ended questions that allowed the respondent to describe a typical day coping with FMS and how CAM may have helped them with their disease. The final section of the questionnaire collected demographic information about the respondent. The study 
investigators participated in a series of meetings to evaluate the questionnaire rationale, content validity, practicality, and functionality. Subsequent to each meeting, revisions were made based on discussions.

The study investigators obtained approval from the FMS clinic physicians prior to implementation of the study. After the clinic manager explained the research study to the clinic staff, a medical assistant at the clinic identified patients diagnosed with FMS who had scheduled clinic visits during the study timeframe. To facilitate distribution, questionnaires were attached to each identified patient chart. Study participation was discussed with the patient at the time of their visit. Patients were instructed to return the questionnaire via US Mail using the pre-paid, self-addressed return envelope included with the cover letter and questionnaire. Non-respondents were not contacted and follow-up questionnaires were not distributed to provide additional reassurance that participation was not tracked.
A research assistant under the supervision of the study investigators entered the raw data into a database. After entering data from each respondent, the research assistant double-checked the data entry on a separate date to ensure accuracy of input. The study investigators adjudicated the final coding of difficult to interpret survey responses such as selection of more than one response choice or the mark of a response choice outside of the designated response field. Data were exported to Stata $^{8}$ for analysis. An a priori significance level of 0.05 was established for all statistical testing.

Descriptive statistics were used to profile the respondent sample for each questionnaire. The prevalences of "ever-use" of the various types of CAM were reported as proportions. The individual relationships between discussing CAM with healthcare providers and the "ever-use" of dietary and herbal supplements were explored using $2 \times 2$ contingency tables.

\begin{tabular}{|c|c|c|c|}
\hline & Response Category & $\mathrm{n}$ & $(\%)^{a}$ \\
\hline \multicolumn{4}{|l|}{ Sex } \\
\hline & Male & 6 & 11.3 \\
\hline & Female & 47 & 88.7 \\
\hline \multicolumn{4}{|l|}{ Race/Ethnicity } \\
\hline & White & 52 & 100 \\
\hline & Non-white & 0 & - \\
\hline \multicolumn{4}{|c|}{ Highest Educational Attainment } \\
\hline & High School Graduate or GED ${ }^{b}$ & 19 & 35.9 \\
\hline & Some College, No Degree & 16 & 30.2 \\
\hline & Associate / Vocational Degree & 8 & 15.1 \\
\hline & Bachelors Degree & 8 & 15.1 \\
\hline & Master's, Doctorate or Professional Degree & 2 & 3.8 \\
\hline \multicolumn{4}{|c|}{ Annual Household Income, US\$ } \\
\hline & $<20,000$ & 10 & 20 \\
\hline & 20,000 to 34,999 & 13 & 26 \\
\hline & 35,000 to 54,999 & 16 & 32 \\
\hline & 55,000 to $\$ 74,999$ & 5 & 10 \\
\hline & $\geq 75,000$ & 6 & 12 \\
\hline \multicolumn{2}{|c|}{ Age, in years [mean $(\mathrm{sd}), \mathrm{n}]$} & \multicolumn{2}{|c|}{55.6 (11.3), 50} \\
\hline \multicolumn{4}{|c|}{ Years since diagnosis with $\mathrm{FMS}^{\mathrm{C}}$} \\
\hline & $<1$ year ago & 5 & 9.3 \\
\hline & $1-2$ years ago & 6 & 11.1 \\
\hline & $3-4$ years ago & 10 & 18.5 \\
\hline & 5 or more years ago & 33 & 61.1 \\
\hline \multicolumn{4}{|c|}{ Average visit schedule to clinic for $\mathrm{FMS}^{\mathrm{C}}$} \\
\hline & Once a month & 4 & 7.8 \\
\hline & Every 3 months & 20 & 39.2 \\
\hline & Every 6 months & 25 & 49.0 \\
\hline & Once a year & 2 & 3.9 \\
\hline \multicolumn{4}{|c|}{ Had discussion about Complementary and Alternative Therapy use with: } \\
\hline & Clinic Rheumatologist & 29 & $53.7^{\mathrm{d}}$ \\
\hline & Clinic Physician Assistant & 12 & $22.2^{\mathrm{d}}$ \\
\hline & Primary Care Physician & 21 & $38.9^{\mathrm{d}}$ \\
\hline & Pharmacist & 8 & $14.8^{\mathrm{d}}$ \\
\hline & Any Healthcare Provider Listed Above & 39 & $72.2^{\mathrm{d}}$ \\
\hline \multicolumn{2}{|c|}{$\begin{array}{l}\text { Reported Any Type of Complementary and Alternative Medicine } \\
\text { Use }\end{array}$} & 50 & $92.6^{\mathrm{d}}$ \\
\hline \multicolumn{4}{|c|}{ 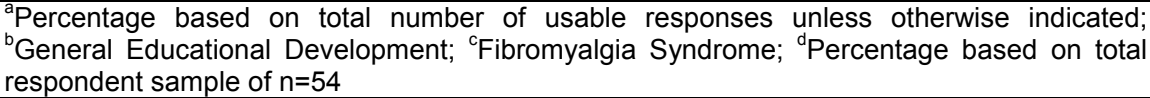 } \\
\hline
\end{tabular}

\section{RESULTS}

Forty-seven percent of questionnaires distributed (54/115) were returned for analysis. As a result of some unanswered items, the sample sizes for individual questionnaire items varied slightly from the number of returned questionnaires. Thus, individual results were reported based on usable responses and are noted in the tables. 
Age, sex, race, education level, and annual household income are reported in Table 1. In general, the study sample was predominantly female $(88.7 \%)$, well educated $(64.2 \%$ with at least some post-high school education), with a mean age of 55.6 years. All respondents reported their race as White.

The majority (61.1\%) of respondents reported being diagnosed with FMS five or more years prior to completing the questionnaire (Table 1). More than $88 \%$ of respondents reported visiting the clinic every three to six months with nearly $8 \%$ visiting the clinic on a monthly basis. A majority $(72.2 \%)$ of the total number of respondents reported discussing CAM with a clinic rheumatologist, physician assistant, primary care provider, or a pharmacist. However, the clinic rheumatologist and the primary care physician were health care professionals with whom respondents most commonly discussed CAM at $53.7 \%$ and $38.9 \%$, respectively (Table 1 ). In contrast, only $14.8 \%$ of the total number of respondents discussed CAM with their pharmacist.

Most respondents (92.6\%) reported "ever-using" at least one type of CAM (Table 1) while $85.2 \%$ reported "ever-using" two or more types of CAM. Exercise $(92.2 \%)$ followed by chiropractic treatment $(48.1 \%)$, lifestyle and diet $(45.8 \%)$, relaxation therapy $(44.9 \%)$, and dietary and herbal supplements $(36.5 \%)$ were the most commonly reported CAM "ever-used" by respondents (Table 2 ). Dietary and herbal supplements with the highest prevalence of "ever-use" were magnesium (19.2\%), guaifenesin $(11.5 \%)$, and methylsulfonylmethane (MSM) (9.6\%).

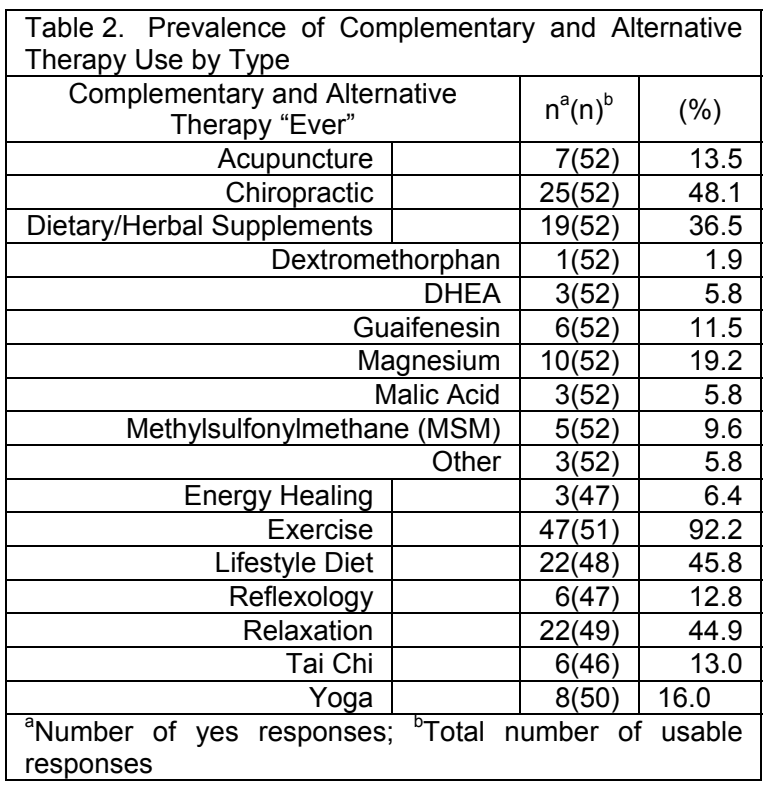

One may ask whether dietary and herbal use is associated with discussion of CAM with a healthcare provider. Our data suggest that there is a relationship between dietary and herbal "ever" use and discussion with a pharmacist, but not with the clinic rheumatologist, clinic physician assistant or primary care provider. (Table 3) A significantly higher proportion of respondents who "ever-used" dietary and herbal supplements discussed CAM with a pharmacist [6/19 or $31.6 \%$ ] compared to those who never reported dietary and herbal supplement use [2/33 or $6.1 \%$ ] [chi square $=6.03$, $p=0.014]$. whereas the relationships between everusing dietary and herbal supplements and discussing CAM with either the clinic rheumatologist, clinic physician assistant, or the primary care provider were not significant.

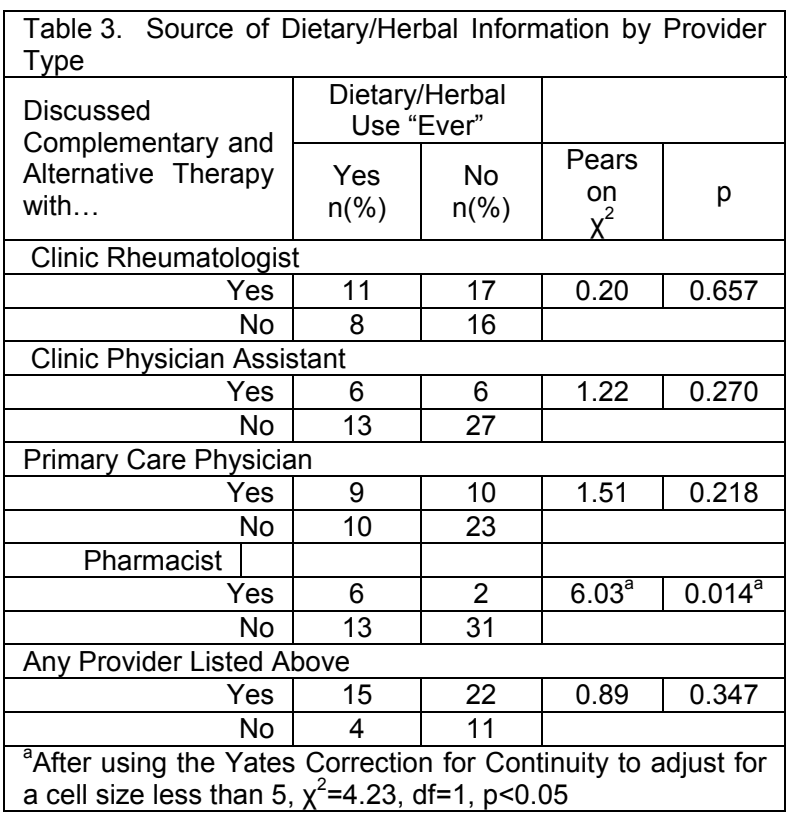

\section{DISCUSSION}

This pilot study demonstrated that self-reported CAM use is common among primary care FMS patients. We included only patients who had attended a rheumatology physician practice. Thus, our sample could not account for any patients who use CAM solely in place of allopathic medicine. Although one previous study on rheumatologic conditions reported a lower prevalence of CAM use for FMS $(24 \%)$, the reported "ever-use" of CAM in our study $(92.6 \%)$ more closely mirrored a recently published study from the Mayo Clinic that indicated virtually all patients used some form of CAM in their tertiary-care population $(98 \%)^{5,9}$

Several interesting points can be drawn from our questionnaire. Most patients $(85.2 \%)$ in our sample had used more than one type of CAM. In general, most respondents reported a perceived benefit from CAM based on responses to open-ended questions describing a typical day coping with symptoms of FMS and how CAM has helped.

Types of exercise, reported in the open-ended questions, such as warm water aerobics, stretching and walking were utilized most frequently. These types of exercise are also commonly recommended for patients with rheumatic disease and are generally considered mainstream therapy for these conditions. In contrast, chiropractic treatment, reported as the second most frequently used CAM, has few well-designed studies and has not been shown to be beneficial according to a review of CAM efficacy in FMS. ${ }^{10}$ Considering the goals of pharmaceutical care, perhaps the greatest cause for 
concern from a safety and efficacy perspective is that over one-third of the respondents reported dietary or herbal supplements "ever-use", but less than one-third of the "ever-users" discussed CAM with a pharmacist. Self-medicating with nonprescription or dietary and herbal supplements presents additional risks to patients that may be exacerbated without proper counseling and monitoring. For example, the most frequently used supplement was magnesium. Serum magnesium abnormalities have been reported in patients with FMS and has been suggested as helpful for muscle pain. ${ }^{11}$ However, in patients with reduced renal function, using high doses of magnesium can cause central nervous system and respiratory depression, hypotension, and heart block. Coupled with our finding that patients do not always discuss CAM therapy, causal factors of adverse events (related to CAM use) may be difficult to ascertain when no documentation of usage exists.

In addition to safety concerns related to adverse events and drug or disease interactions, unnecessary financial burden is incurred when patients use products such as guaifenesin ${ }^{12}$ that have been demonstrated to be ineffective in FMS. Despite the lack of evidence, $11.5 \%$ of respondents in our study reported use of guaifenesin.

It is important for healthcare workers to avoid assuming that all patients understand the terminology "dietary or herbal supplements" and "complementary or alternative medicine" when performing medical condition or drug histories. While patients may be reluctant to provide this information, they also may not perceive these products to be drug therapy. For example, $18.2 \%$ of respondents who reported that they did not use "dietary or herbal supplements" also reported that they used products that fall under this heading such as magnesium, MSM, and Dehydroepiandrosterone (DHEA) in our study. Other studies have found that patients who are asked about specific conditionrelated CAM usage are more likely to provide such information. ${ }^{13}$ Providing specific names of dietary or herbal supplements used for a particular condition in question, such as magnesium, DHEA, etc. may be necessary to extract adequate usable information from patients when performing medication reconciliation activities.

Previous studies indicated that less than $50 \%$ of patients discuss CAM with health care providers. $^{14,15}$ Our study showed that $72.2 \%$ of respondents indicated some discussion about CAM with a health care provider. Although this appears to be a positive increase and may indicate that patients and physicians are becoming more open to these discussions, there is a concern about the small proportion of respondents who discussed CAM with a pharmacist found in this study (14.8\%). Rao, et al. found that patients reported, "not being asked" as the number one reason for not reporting use of supplements, instead of the commonly held belief that they were afraid their physician would disapprove. The second most frequent reason for not reporting was "forgot to tell". ${ }^{13}$ Pharmacists cannot be effective monitors of drug therapy if incomplete information is present. Unfortunately in our study, pharmacists who are uniquely positioned to use this information appeared to have the least discussion with this population of patients. Perhaps it can be inferred that if the pharmacist doesn't ask (and ask using specific names), patients don't tell.

This pilot study is not without limitations. First, we assume that all respondents understood questionnaire instructions and that they completed the individual items accurately and honestly as this was a self-completed questionnaire in an unsupervised setting. Although the response rate approached $50 \%$, we also do not know whether non-respondents are comparable to respondents and would have reported similar CAM use. By design we provided assurances of anonymity to improve response and therefore characteristics of the respondents and non-respondents could not be tracked and compared. Finally, the demographic homogeneity of the current study sample precludes generalizations to more diverse FMS patient groups and practices. However, the results of this study serve as a basis for broader exploration.

\section{CONCLUSIONS}

CAM use is common among primary care FMS patients. Exercise and lifestyle changes, chiropractic and dietary and herbal supplements were reported most frequently in our study. More than two-thirds of respondents discussed CAM use with a healthcare worker, but less than 15\% discussed CAM with a pharmacist specifically. Coupled with results from other research, this study reinforced the need to query patients specifically about CAM, including dietary and herbal supplements.

\section{CONFLICT OF INTEREST}

None declared.

\section{References}

1. Doron Y, Peleg R, Peleg A, Neumann L, Buskila D. The clinical and economic burden of fibromyalgia compared with diabetes mellitus and hypertension among Bedouin women in the Negev. Fam Pract. 2004; 21:415-9.

2 Robinson RL, Birnbaum HG, Morley MA, Sisitsky T, Greenberg PE, Claxton AJ. Economic cost and epidemiological characteristics of patients with fibromyalgia claims. J Rheumatol. 2003;30:1318-25.

3 Solomon $\mathrm{DH}$, Liang MH. Fibromyalgia: scourge of humankind or bane of a rheumatologist's existence? Arthritis Rheum. 1997 ; $40: 1553-5$.

4 Littlejohn GO, Walker J. A realistic approach to managing patients with fibromyalgia. Curr Rheumatol Rep. 2002 ;4:28692. 
5 Rao JK, Mihaliak K, Kroenke K, Bradley J, Tierney WM, Weinberger M. Use of Complementary Therapies for Arthritis among Patients of Rheumatologists Ann Intern Med. 1999;131:409-416.

6 Mannel M. Drug Interactions with St John's Wort : Mechanisms and Clinical Implications. Drug Saf. 2004;27:773-97.

7 Barbour C. Use of complementary and alternative treatments by individuals with fibromyalgia syndrome. J Am Acad Nurse Pract. 2000;12:311-6.

8 StataCorp. (2003). Stata Statistical Software: Release 8.0. College Station, TX: Stata Corporation.

9 Wahner-Roedler DL, Elkin PL, Vincent A, Thompson JM, Oh TH, Loehrer LL, et al. Use of complementary and alternative medical therapies by patients referred to a fibromyalgia treatment program at a tertiary care center. Mayo Clin Proc. 2005 Jan;80(1):55-60.

10 Sarac AJ, Gur A. Complementary and alternative therapies in fibromyalgia. Curr Pharm Des. 2006;12:47-57.

11 Russell IJ, Michalek JE, Flechas JD, Abraham GE. Treatment of fibromyalgia syndrome with Super Malic: a randomized, double blind, placebo controlled, crossover pilot study. J Rheumatol. 1995;22:953-8

12 Bennett RM, DeGarmo P, Clark SR A 1 year double blind placebo-controlled study of guaifenesin in fibromyalgia". Arthritis and Rheumatism 1996;39: S212.

13 Rao JK, Mihaliak K, Kroenke K, Bradley J, et al. Use of complementary therapies for arthritis among patients of rheumatologists. Ann Intern Med. 1999;131:409-16.

14 Visser GJ, Peters L, Rasker JJ. Rheumatologists and their patients who seek alternative care: an agreement to disagree. Br J Rheumatol. 1992;31:485-90.

15 Vecchio PC. Attitudes to alternative medicine by rheumatology outpatient attenders. J Rheumatol. 1994;21:145-7. 